\title{
Inflammatory biomarkers responses after acute whole body vibration in fibromyalgia
}

\author{
V.G.C. Ribeiro ${ }^{1}$, V.A. Mendonça $a^{1,2,3}$, A.L.C. Souza ${ }^{2}$, S.F. Fonseca ${ }^{1}$, A.C.R. Camargos ${ }^{2,4}$, \\ V.K.S. Lage ${ }^{1}$, C.D.C. Neves ${ }^{1}$, J.M. Santos ${ }^{2}$, L.A.C. Teixeira ${ }^{2}$, E.L.M. Vieira ${ }^{5}$, A.L. Teixeira Junior ${ }^{5}$, \\ B. Mezêncio ${ }^{6}$, J.S.C. Fernandes ${ }^{7}$, H.R. Leite ${ }^{1,2,3}$, J.R. Poortmans ${ }^{8}$ and A.C.R. Lacerda ${ }^{1,2,3}$ \\ ${ }^{1}$ Programa Multicêntrico de Pós-Graduação em Ciências Fisiológicas, Sociedade Brasileira de Fisiologia, Diamantina, MG, Brasil \\ ${ }^{2}$ Programa de Pós-Graduação em Reabilitação e Desempenho Funcional, Universidade Federal dos Vales do Jequitinhonha e \\ Mucuri, Diamantina, MG, Brasil \\ ${ }^{3}$ Departamento de Fisioterapia, Faculdade de Ciências Biológicas e da Saúde, Universidade Federal dos Vales do Jequitinhonha e \\ Mucuri, Diamantina, MG, Brasil \\ ${ }^{4}$ Departamento de Fisioterapia, Escola de Educação Física, Fisioterapia e Terapia Ocupacional, \\ Universidade Federal de Minas Gerais, Belo Horizonte, MG, Brasil \\ ${ }^{5}$ Escola de Medicina, Universidade Federal de Minas Gerais, Belo Horizonte, MG, Brasil \\ ${ }^{6}$ Escola de Educação Física e Esporte, Universidade de São Paulo, São Paulo, SP, Brasil \\ ${ }^{7}$ Departamento de Agronomia, Faculdade de Ciências Agrárias, Universidade Federal dos Vales do Jequitinhonha e Mucuri, \\ Diamantina, MG, Brasil \\ ${ }^{8}$ Faculty of Motor Sciences, Université of Libre de Bruxelles, Brussels, Belgium
}

\begin{abstract}
The aims of this study were 1) to characterize the intensity of the vibration stimulation in women diagnosed with fibromyalgia (FM) compared to a control group of healthy women (HW) matched by age and anthropometric parameters, and 2) to investigate the effect of a single session of whole body vibration (WBV) on inflammatory responses. Levels of adipokines, soluble tumor necrosis factor receptors (sTNFr1, sTNFr2), and brain-derived neurotrophic factor (BDNF) were determined by enzyme-linked immunosorbent assay. Oxygen consumption $\left(\mathrm{VO}_{2}\right)$ was estimated by a portable gas analysis system, heart rate (HR) was measured using a HR monitor, and perceived exertion (RPE) was evaluated using the Borg scale of perceived exertion. Acutely mild WBV increased $\mathrm{VO}_{2}$ and $\mathrm{HR}$ similarly in both groups. There was an interaction (disease vs vibration) in RPE $(P=0.0078)$, showing a higher RPE in FM compared to HW at rest, which further increased in FM after acute WBV, whereas it remained unchanged in HW. In addition, there was an interaction (disease vs vibration) in plasma levels of adiponectin $(P=0.0001)$, sTNFR1 $(P=0.000001)$, sTNFR2 $(P=0.0052)$, leptin $(P=0.0007)$, resistin $(P=0.0166)$, and $B D N F$ $(P=0.0179)$. In conclusion, a single acute session of mild and short WBV can improve the inflammatory status in patients with $\mathrm{FM}$, reaching values close to those of matched HW at their basal status. The neuroendocrine mechanism seems to be an exercise-induced modulation towards greater adaptation to stress response in these patients.
\end{abstract}

Key words: Biomarkers; Fibromyalgia; Clinical trial; Inflammation; Acute exercise

\section{Introduction}

Fibromyalgia (FM) is characterized by chronic widespread pain of more than 3 months duration (1). Clinical studies have observed that FM is associated with immune dysregulation of proinflammatory biomarkers, affecting the neural function of pain-related neurotransmitters (2). Blood interleukin (IL)-8 level is increased in FM (2) suggesting that IL-8 could be an "inflammatory marker" for FM syndrome (2). Tumor necrosis factor (TNF) is another potent cytokine, secreted mainly by macrophages, with mostly proinflammatory and catabolic actions, together with high levels in the serum of FM subjects (3). This marker has soluble receptors (sTNFR1 and sTNFR2) which compete with the surface receptor by binding to TNF and modulating its inflammatory activity, and it has been suggested that they function as physiological attenuators of the degradative activity of TNF (4). Whereas the soluble receptors are generally more stable in the circulation than the cytokines, the former can be more reliable markers of chronic inflammation (5).

Several factors termed adipokines, mainly produced in the adipose tissue have been found to be important

Correspondence: A.C.R. Lacerda: <lacerdaacr@gmail.com | lacerda.acr@ufvjm.edu.br> 
regulators in both inflammation and nutrition, which may affect neuroendocrine regulation of pain and fatigue through several pathways (6). Adiponectin detects metabolic stress and modulates the metabolic adaptation targeting the innate immune system under pathological conditions, such as FM, demonstrating that this hormone seems to play an important role in regulating immune function during inflammation incidents (7).

Other important adipokines in metabolic and inflammatory processes are leptin and resistin. Leptin plays a regulatory role in immunity, inflammation, and hematopoiesis. Leptin and its receptor share structural and functional similarities with the interleukin- 6 family of cytokines, and they affect cytokine production, activation of monocytes/ macrophages, wound healing, angiogenesis, and hematopoiesis (8). The role of resistin in the metabolic profile is unclear; however, its role in inflammatory processes is stimulated by proinflammatory cytokines such as TNF and IL-6 (9). Moreover, they may induce the expression of these cytokines in adipose tissue and peripheral blood mononuclear cells (10). Therefore, it might be speculated that those adipokines may represent a link between inflammation and metabolic signaling.

Brain-derived neurotrophic factor (BDNF) is also intimately connected with central and peripheral molecular processes of energy metabolism and homeostasis (11). It is considered an essential neurotrophin synthesized by skeletal muscle cells in response to contraction stimulation together with enhancing fat oxidation via activation of adenosine monophosphate-activated protein kinase (12). Neurotrophin expression is usually enhanced in chronic inflammatory diseases because of its role in energy homeostasis (13). However, the current literature has evidenced that serum levels of BDNF did not differ significantly when comparing FM patients and controls (14).

Several therapies have been investigated to treat the symptoms associated with FM. To the best of our knowledge, only two studies have evaluated the acute effects of exercise in patients with FM. Bote and colleagues (15) demonstrated that mild cycling improve the inflammatory and stress status of FM. However, exhaustive exercise cannot be considered an anti-inflammatory stimulus (16).

Whole body vibration (WBV) has been proposed as a beneficial exercise modality for the treatment of FM $(17,18)$ and other chronic inflammatory diseases (19). However, no study to date investigated whether this type of therapy could improve the inflammatory status in patients with FM. Although contraindications for exercise in patients with FM have not been described, it is mandatory to define the time and intensity of exercise programs to obtain responses that lead to anti-inflammatory effects (1).

The objectives of this study were: 1) To characterize the intensity of vibration stimulation in women diagnosed with FM as compared to a control group of healthy women $(\mathrm{HW})$, matched by age and anthropometric parameters and 2) to investigate the effect of a single bout of WBV on inflammatory biomarker levels (adiponectin, sTNFr1, sTNFr2, resistin, leptin, BDNF, and IL-8).

\section{Material and Methods}

\section{Ethical statement}

This is a prospective 1:1 case-control paired study that assessed variables before and immediately after an acute session of WBV. This study was conducted in accordance with the ethical principles for research involving humans (principles of the Declaration of Helsinki) and received approval from the Ethics Committee of the Universidade Federal dos Vales do Jequitinhonha e Mucuri (No. 1.461. 311), and Brazilian Guidelines (Res. CNS 196/96, No. RBR-36d8nf). All participants were informed about the study procedures and provided their written consent to participate in this study.

\section{Study design and subjects}

The volunteers were recruited from April to June, 2016 through the waiting list of physiotherapy from Universidade Federal dos Vales do Jequitinhonha e Mucuri, Basic Health Units, Specialized Center for Rehabilitation, and announcements on the radio of Diamantina, MG, Brazil.

A sample size of 38 volunteers was required to meet the significance level of 0.05 and power of $80 \%$ before the beginning of this study. Thus, a total of 116 women were initially assessed for eligibility. Of these, 76 were excluded as they did not meet the inclusion criteria $(n=62)$, declined to participate $(n=11)$, or for other reasons $(n=3)$. The remaining 40 women were allocated to a fibromyalgia group $(n=20)$ or a healthy-paired group $(n=20)$. Both groups were submitted to vibration exposure. However, one subject from each group was excluded because blood biomarkers were identified as outliers through Grubbs' test, also called the ESD method (Figure 1). Thus, nineteen women diagnosed with FM according to the American College of Rheumatology criteria (1) were enrolled in the study. Some anthropometric, demographic, and clinical data are shown in Table 1. Participants were asked to fill out a questionnaire about their lifestyle (diet, habits, etc.), medication, and other previous or current concomitant illnesses. The subjects completed the "Physical Activity Readiness Questionnaire (PAR-Q)" (15) as well as the "Fibromyalgia Impact Questionnaire" (FIQ) (20). They were also characterized by the "Beck Depression Inventory and the sitting-rising test" $(21,22)$ in order to confirm that all FM volunteers had a chronic and stable disease status. The exclusion criteria were the presence of any concomitant disease that could be exacerbated by physical activity, pregnancy, inflammatory diseases, and degenerative, joint, respiratory, or cardiovascular disease. Other exclusion criteria were: 1) volunteers being followed by a psychiatrist or those who performed physical activity more than two times per week; 2) subjects who displayed any of the possible contraindications for WBV 


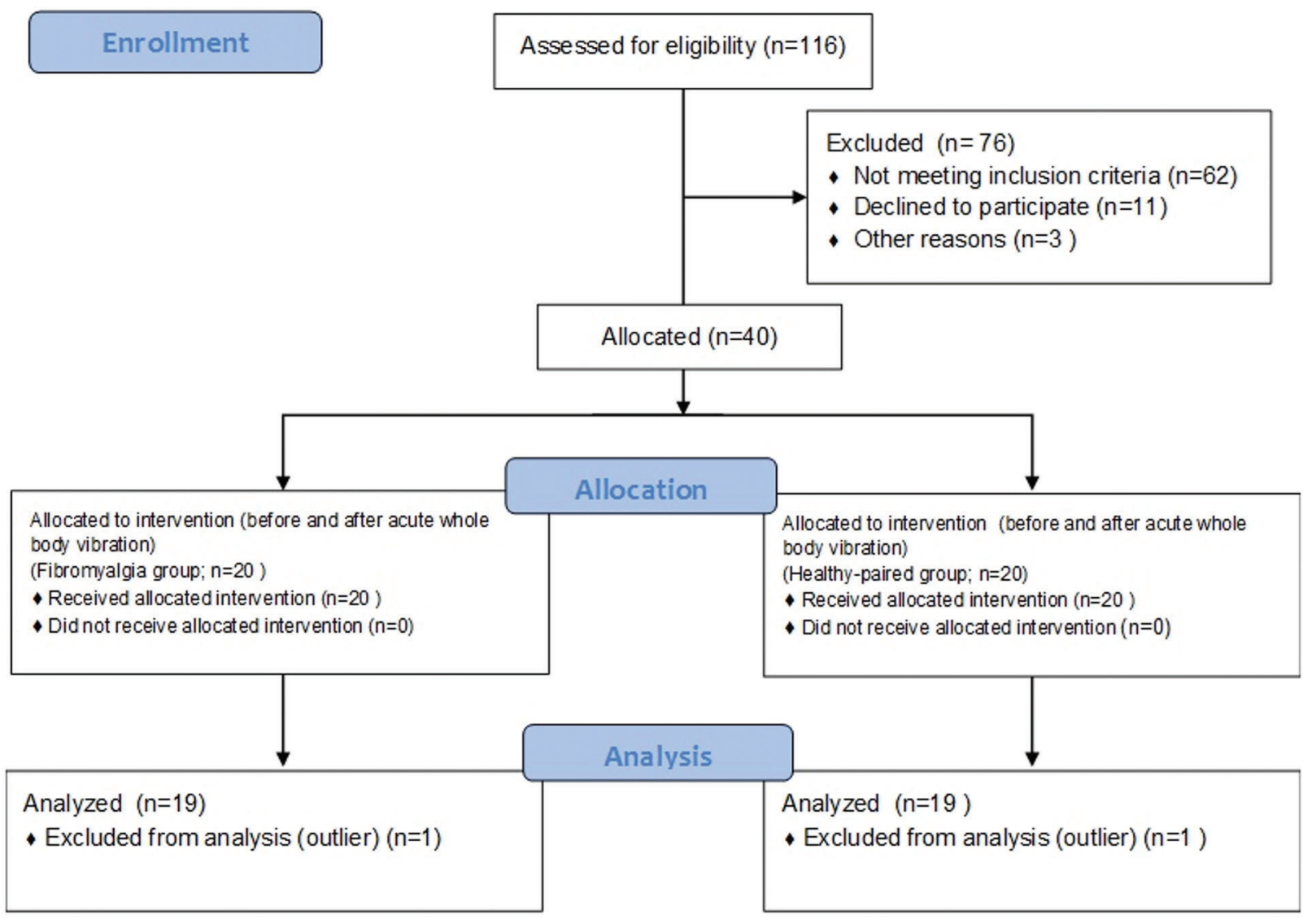

Figure 1. Study flowchart.

Table 1. Characteristics of study subjects.

\begin{tabular}{lrcc}
\hline & $\mathrm{HW}(\mathrm{n}=19)$ & $\mathrm{FM}(\mathrm{n}=19)$ & $\mathrm{P}$ \\
\hline Age (years) & $51.05 \pm 1.90$ & $52.16 \pm 1.81$ & 0.61 \\
Weight $(\mathrm{kg})$ & $73.38 \pm 3.09$ & $74.79 \pm 3.20$ & 0.76 \\
Height $(\mathrm{m})$ & $1.58 \pm 0.02$ & $1.58 \pm 0.01$ & 0.68 \\
BMI $\left(\mathrm{kg} / \mathrm{cm}^{2}\right)$ & $29.65 \pm 1.28$ & $29.71 \pm 1.09$ & 0.97 \\
Tender points & $0.85 \pm 0.45$ & $14.1 \pm 0.72^{*}$ & $<0.0001$ \\
BDI & $10.90 \pm 1.16$ & $22.10 \pm 1.88^{*}$ & 0.0002 \\
SUT & $12.84 \pm 0.38$ & $8.57 \pm 0.79^{*}$ & 0.0002 \\
FIQ & - & $75.58 \pm 4.40$ & - \\
Time from diagnosis (years) & - & $>2^{* *}$ & - \\
IL-8 $(\mathrm{pg} / \mathrm{mL})$ & $4.13 \pm 0.74$ & $7.42 \pm 1.62$ & 0.006 \\
\hline
\end{tabular}

HW: healthy women; FM: fibromyalgia; BMl: body mass index; BDI: Beck Depression Inventory; FIQ: Fibromyalgia Impact Questionnaire; SUT: Sit-up test; IL8: interleukin 8. ${ }^{* *} 100 \%$ of volunteers. Data are reported as means $\pm S E$. ${ }^{*} P<0.05$ (Tukey's test).

stimulus, such as acute hernia, stroke, diabetes, epilepsy, metabolic or neuromuscular diseases, orthopedic and prosthetic lesions (23); and 3) women who were taking oral or topical immunosuppressive medication (corticosteroids) or anti-cytokine therapy that could influence the level of cytokines. The control group was composed of 19 healthy women matched by age, body mass, height, and medication intake, without any pain disorders or infectious illness. 
The same requirements were applied to both groups. All volunteers were physically inactive, did not participate in exercise programs during the previous 24 months, and were non-smokers and non-consumers of alcohol.

\section{Procedures}

One week before the trial, all the volunteers were familiarized with the vibrating platform. The session was scheduled during the day and carried out in a reserved room with the temperature maintained at approximately $23^{\circ} \mathrm{C}$. Anthropometric characterization, evaluation of tender points, questionnaires, and tests to evaluate the muscular performance of the lower limbs (sitting and standing) were also carried out. The evaluation was conducted by the same investigator to ensure equal instruction. Analysis of the questionnaires was performed by a blind researcher (24).

Measurement of body weight was performed by an anthropometric mechanical scale, equipped with a stadiometer (Seca, Germany). The body mass index (BMI) was determined as the total body weight divided by height squared $\left(\mathrm{kg} / \mathrm{m}^{2}\right)(25)$.

The assessment of tender points was performed by palpation. A tender point was considered positive when painful discomfort was triggered after digit pressure of around $4 \mathrm{~kg} / \mathrm{cm}(1)$.

The health status, functional capacity, and main symptoms of FM were assessed using the "Brazilian version of the FIQ" (20). Evaluation of depression was performed using the Beck Depression Inventory (21). Muscle strength of the lower limbs was evaluated by the sit-and-stand chair test (22).

\section{Trial}

All volunteers arrived at the experimental center at 7:30 am, after fasting for at least $8 \mathrm{~h}$, including not taking regular medication (15). The experimental protocol began with the subjects remaining at rest for 30 min. During this period, the volunteers were instructed to remain seated, and not to perform sudden movements.

The vibration exposure consisted of performing squatting exercises with a vibration stimulus (frequency of $40 \mathrm{~Hz}$ and amplitude of $4 \mathrm{~mm}$ ) performed on a commercial model of vibration platform (FitVibe, GymnaUniphy NV, Belgium). This vibration frequency and amplitude was selected because this prototype renders an acceleration range of $2-5 g(26)$. Acceleration is a variable used to quantify the intensity of the vibration stimulus (19).

During vibration stimulus, the volunteers performed 8 series of $40 \mathrm{~s}$ of squatting exercises. During each exercise series, the volunteer was instructed, by the same examiner blind to the group assignments of the participants, to perform a semi complete extension (ca. $10^{\circ}$ ) to a $60^{\circ}$ angle knee bend. The $60^{\circ}$ angle was measured for each volunteer by using a universal goniometer before initiating the exercise series, and a barrier was placed at the gluteal region to limit the flexion degree of the knees.
To control the time of each squat, an examiner instructed the individuals to bend their knees to an $60^{\circ}$ angle for $3 \mathrm{~s}$ and then to an $10^{\circ}$ angle for $3 \mathrm{~s}$, over the $40 \mathrm{~s}$ of each series, for a total of 5 repetitions each. The participants were also instructed to remain in the correct position with their feet on the platform and their spine, arms, and head also in their instructed position (23).

\section{Inflammatory biomarkers}

Peripheral blood samples were collected before and immediately after exercise for each volunteer, and plasma was prepared and stored at $-80^{\circ} \mathrm{C}$ until required. IL-8 level was measured using the cytometric bead arrays kit (BD Bioscience, USA) according to the manufacturer's protocol. Samples were acquired in a FACSCanto flow cytometer (BD Biosciences) and analyzed using the FCAP Array v1.0.1 software (Soft Flow Inc., Hungary). The detection limits were $0.2 \mathrm{pg} / \mathrm{mL}$ for IL-8 level.

Adiponectin, plasma soluble TNF receptor (sTNFR1, sTNFR2), leptin, resistin, and BDNF levels were measured using conventional sandwich enzyme-linked immunosorbent assay kits (DuoSet, R\&D Systems, USA), according to the manufacturer's instructions. The detection limits were $5.0 \mathrm{pg} / \mathrm{mL}$ for all kits.

\section{Evaluation of oxygen consumption and heart rate}

To measure oxygen consumption, a K4b2 portable gas analysis system (Cosmed, Italy) was used to transmit breath-by-breath data to a computer throughout the experimental protocol. HR was measured and registered after 30 minutes at rest and immediately after vibration exposure (Polar RS800sd) (23).

The Borg Scale of Perceived Exertion (RPE) and heart rate were measured and registered after 30 minutes at rest and immediately after vibration exposure (27).

\section{Statistical analyses}

Data are reported as means $\pm S E$. These are two experiments with common treatments. Tukey's test was used to compare the mean with a $5 \%$ significance level.

The model used (28) was: $y_{i j k}=m+a_{i}+b_{j}+a b_{i j}+$ $r_{k(j)}+e_{i k(j)}$ where: $m=$ general mean; $a_{i}=$ effect of vibration

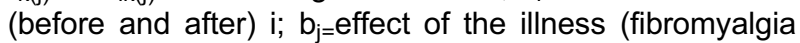
and control groups) $\mathrm{j}$; $\mathrm{ab}_{\mathrm{ij}}=$ effect of the interaction between

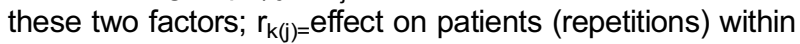
groups (control and fibromyalgia); $e_{i k(j)}=$ weighted average error.

\section{Results}

There were no differences between the groups FM and HW with regard to age, body mass, height, or BMl $(P>0.05)$. The FM group had significantly greater tender points than the HW group $(P<0.0001)$. The FM group had higher scores on BDI (49\%), where scores of $17-27$ are characterized as mild depression. The minimum time from 
diagnosis in the FM group was two years. A score of $75.58 \pm$ 4.40 was found in the FM group for the FIQ. Considering the sit-up test, the HW group showed a higher number of repetitions $(12.84 \pm 0.38)$ compared to the FM group $(8.57 \pm 0.79)$, characterizing reduced muscle performance of lower limbs in the FM group. Two volunteers of the FM group failed to make any repetition in this test (Table 1).
Mild vibration exposure increased oxygen consumption and heart rate similarly in both groups. The FM group had a higher RPE, which further increased after vibration stimulus, than the HW group at rest, which remained unchanged (Table 2). However, there was an interaction in the Borg scale of perceived exertion $(p=0.0078)$, shown in (Figure 2G).

Table 2. Oxygen consumption $\left(\mathrm{VO}_{2}\right)$ and heart rate $(\mathrm{HR})$ in $\mathrm{HW}(\mathrm{n}=19)$ and $\mathrm{FM}$ $(n=19)$ groups before and during stimulus of WBV.

\begin{tabular}{lclc}
\hline & $\mathrm{VO}_{2}\left(\mathrm{mLO}_{2} \cdot \mathrm{kg}^{-1} \cdot \mathrm{min}^{-1}\right)$ & $\mathrm{HR}(\mathrm{bpm})$ & RPE scale \\
\hline WH & $2.69 \pm 0.17$ & $73 \pm 1.65$ & $6.21 \pm 0.12$ \\
WH + WBV & $6.33 \pm 0.44^{+}$ & $93 \pm 2.37^{+}$ & $6.79 \pm 0.27$ \\
$\mathrm{FM}$ & $3.10 \pm 0.13$ & $80 \pm 2.38$ & $8.42 \pm 0.54^{*}$ \\
$\mathrm{FM}+$ WBV & $7.31 \pm 0.28^{+}$ & $97 \pm 2.64^{+}$ & $11.42 \pm 0.80^{+* *}$ \\
\hline
\end{tabular}

WH: healthy women; FM: fibromyalgia; WH + WBV: healthy women during whole body vibration; FM + WBV: fibromyalgia women during whole body vibration; HR: heart rate; bpm: beats per minute; RPE: Borg Scale of Perceived Exertion. Data are reported as means $\pm \mathrm{SE}$. ${ }^{*} \mathrm{P}<0.05 \mathrm{FM}$ vs $\mathrm{WH} .{ }^{+} \mathrm{P}<0.05 \mathrm{WBV}$ effect. ${ }^{* *} \mathrm{P}<0.05 \mathrm{FM}+\mathrm{WBV}$ vs WH+ WBV (Tukey's test).
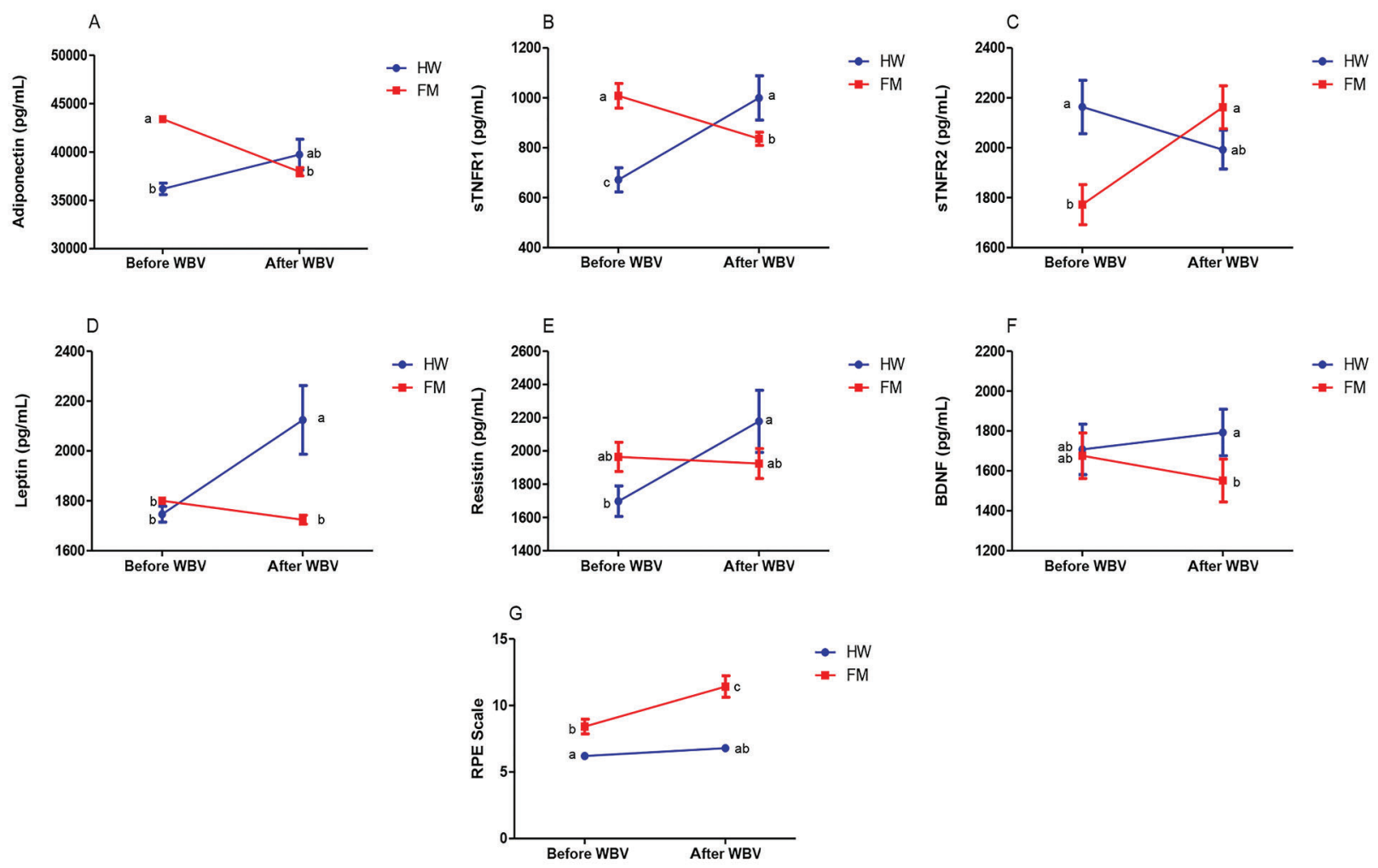

Figure 2. Interaction between biomarkers $(A-F)$ before and after whole body vibration (WBV). Blue represents the healthy women group $(\mathrm{HW}, \mathrm{n}=19)$ and red the fibromyalgia women group $(\mathrm{FM}, \mathrm{n}=19)$. Adiponectin $(A)$, plasma soluble tumor necrosis factor-receptors 1 (sTNFR1) $(B)$ and 2 (sTNFR2) $(C)$, leptin $(D)$, resistin $(E)$, brain-derived neurotrophic factor (BDNF) $(F)$, and Borg Scale of Perceived Exertion (RPE, $G$ ) in healthy women and in fibromyalgia women ( $F M ; n=19)$. Data are reported as means $\pm S E$. $P<0.05$, different small letters indicate significant differences (Tukey's test). 

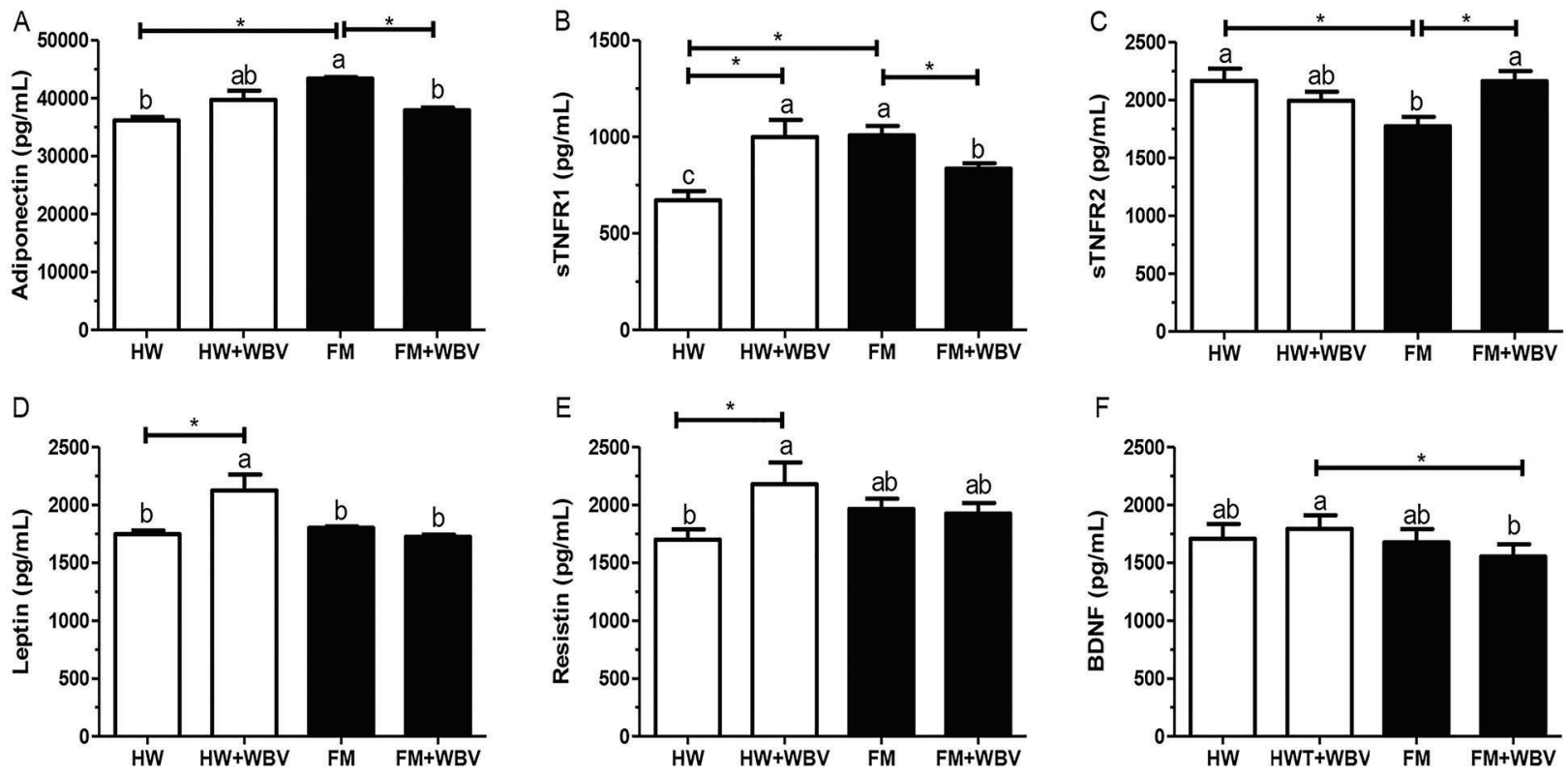

Figure 3. Effect of acute session of whole body vibration (WBV) on plasma levels of adiponectin $(A)$, soluble tumor necrosis factorreceptors $1(\operatorname{sTNFR} 1)(B)$ and $2(\operatorname{sTNFR2})(C)$, leptin $(D)$, resistin $(E)$, and brain-derived neurotrophic factor (BDNF) $(F)$ in healthy women $(H W ; n=19)$ and in fibromyalgia women $(F M ; n=19)$. Data are reported as means $\pm S E . P<0.05$, different small letters and asterisks indicate significant differences (Tukey's test).

Subjects with FM showed higher plasma levels of IL-8 at rest regardless of associated depression (4), demonstrating the occurrence of chronic inflammatory disease (FM: $7.42 \pm 1.62 \mathrm{pg} / \mathrm{mL}$; HW: $4.13 \pm 0.74 \mathrm{pg} / \mathrm{mL} ; \mathrm{P}=0.006$ ). Moreover, the FM group presented increased plasma levels of adiponectin (FM: $43385.80 \pm 274.98$ pg/mL; HW: $36180.61 \pm$ $594.53 \mathrm{pg} / \mathrm{mL} ; \mathrm{P}=0.010$ ), and sTNFR1 (FM: 1008.28 \pm $49.09 \mathrm{pg} / \mathrm{mL} ; \mathrm{HW}: 671.51 \pm 48.24 \mathrm{pg} / \mathrm{mL} ; \mathrm{P}=0.048)$, and decreased plasma concentrations of sTNFR2 (FM: 1772.02 \pm $80.39 \mathrm{pg} / \mathrm{mL}$; HW: $2163.35 \pm 106.71 \mathrm{pg} / \mathrm{mL} ; \mathrm{P}=0.005$ ) compared to the HW group. There was no difference between the groups for plasma levels of leptin, resistin, or BDNF $(P>0.05)$ (Figure 3).

The vibration exposure decreased plasma levels of adiponectin and sTNFR1 and increased levels of sTNFR2 in the FM group. Furthermore, it increased leptin, resistin, and STNFR1 plasma levels in the WH group (Figure 3). There was an interaction in plasma levels of adiponectin $(P=0.0001)$, sTNFR1 $(P=0.000001)$, sTNFR2 $(P=0.0052)$, leptin $(P=0.0007)$, resistin $(P=0.0166)$, and BDNF $(P=0.0179$; Figure 2A-F).

\section{Discussion}

We highlighted the effects of a single acute session of WBV on improving the inflammatory status in patients with $\mathrm{FM}$, redirecting parameters towards metabolic homeostasis, and reaching values close to those of anthropometric parameter and age-matched $\mathrm{HW}$ at their basal status.
To date, this is the first study that investigated the effects of an acute WBV stimulus on the inflammatory response in women with FM.

Although vibration exposure increased oxygen consumption and heart rate equally in both groups, the intensity used was low according to the recommendations of the American College of Sports Medicine (ACSM) and American Heart Association (AHA) (29), representing an additional increase of only $1 \mathrm{MET}\left(3 \mathrm{~mL} \mathrm{O} \cdot \mathrm{kg}^{-1} \cdot \mathrm{min}^{-1}\right)$. This result is consistent with the previous findings of our team that showed an increase of 2 METS, corresponding to a light walk, in a study that evaluated the effect of acute vibration exposure in the elderly (23). Furthermore, although the control group was composed of healthy women, they were about 51 years old, sedentary and overweight.

The FM group exhibited greater perceived exertion at rest and a further increase after acute WBV, whereas it remained unchanged in the HW. However, the exercise was characterized as mild for both groups. Moreover, individuals with FM had lower physical performance in the sit-up test, and attenuated physical and emotional scores in the FIQ, supporting the fact that they have a degenerated exercise perception.

Recent hypotheses of FM etiologies have highlighted the inflammatory disorders accompanied by changes in the neuro-immunoendocrine system (15). Studies have shown that individuals with FM have increased IL-8 plasma levels compared to healthy subjects $(2,15)$. In this study, women with FM showed higher plasma levels of IL-8 and 
sTNFR1 at baseline. Thus, it is possible that the individuals in FM group have an "inflammatory status" inherent to the disease (3).

Moreover, the FM group showed higher plasma levels of adiponectin at rest. Initially this result seems paradoxical, since most studies indicate the anti-inflammatory effect of this adipokine (30). The effect of adiponectin on blood circulation depends on a complex interaction between the disease state and the nature of the inflammatory stimulus (31). However, whether adiponectin acts as an anti or pro-inflammatory factor is still a matter of debate (32). Adiponectin detects metabolic stress and modulates the metabolic adaptation targeting the innate immune system under pathological conditions, such as FM, demonstrating that this hormone appears to play an important role in regulating immune function in inflammation status (7). Studies have shown that increases in adiponectin levels are associated with worsening physical performance via interaction with adipoR 1 and adipoR2 receptors (31). The adipoR1 receptor is abundantly expressed in vascular endothelial cells and skeletal muscle cells, where it regulates glucose and lipid metabolism, while adipoR2 receptor, which acts as a moderate affinity receptor, is mainly expressed in the liver (31). Simultaneous disruption of both receptors nullifies adiponectin binding, resulting in glucose intolerance and insulin resistance (33). Thus, the higher levels of adiponectin in the FM group could contribute to energy imbalance, with structural and functional changes in muscle fibers and hormonal imbalances resulting in a state of myopathy.

The plasma adiponectin levels did not change immediately after acute WBV stimulus in asymptomatic subjects. These results are consistent with current literature (34). Women with FM, who showed higher plasma level of adiponectin at rest, had a reduction in adiponectin levels after WBV stimulus. Although mild and of short duration, this stimulus appears to be beneficial, since it indicates a reduction of adiponectin receptor resistance in the peripheral muscle, contributing to metabolic homeostasis.

The FM group also showed higher plasma levels of sTNFR1 at rest. It appeared that this increase occurred as an attempt to control the chronic systemic inflammation. Thus, we hypothesized that the increase in plasma levels of sTNFR1 occurred while trying to promote inhibition of catabolic action of TNF, inactivating the consequent inhibition of its binding to membrane receptors, together with a reduced supply of its own membrane receptors. STNFR1 soluble receptor is derived by the proteolytic cleavage of plasma membrane-expressed sTNFR1 catalyzed by TNF converting enzyme (TACE), modulating its inflammatory activity probably by attenuating the harmful activity of TNF (4). However, since adiponectin and TNF inhibit each other (35), the increase in soluble receptor levels of sTNFR1 suggests that this control did not actually occur efficiently.
In healthy women, vibration exposure promoted an increase in plasma sTNFR1 levels. By contrast, the antiinflammatory effects induced by mild stimulus in patients with FM could also be considered a positive effect on homeostatic adjustment involved in inflammation-stress feedback mechanisms (15).

Regarding sTNFr2 soluble receptor, we observed lower blood levels in women with FM at rest. It seems that hyperadiponectinemia plays a role in reducing the secretion of this receptor (36). However, this mechanism remains unclear. Moreover, once the intracellular actions of TNF are mostly mediated by sTNFR1 and sTNFR2 (4), it is possible to infer that this marker did not act efficiently to maximize the association between TNF and sTNFR1.

Other important adipokines in the inflammatory response and potential regulators of metabolic function are leptin and resistin (37). The inflammatory and metabolic modulator role of adipokines may have influenced the similarity in blood baseline levels in subjects with FM and HW. However, in situations of metabolic imbalance and consequent alertness, such as during acute stimulation WBV, blood levels of this biomarker increase systemically (38). Since patients with FM have a constant metabolic and inflammatory stress, the turnover of leptin appears to have a higher threshold to stressful stimuli, which could explain the maintenance of blood levels of this biomarker after WBV stimulus in these patients (15).

Basal blood levels of resistin were similar between groups. This finding is similar with Bjersing and colleagues (6) study, which also identified stable baseline levels of these adipokines in overweight/obese subjects with FM. However, acute vibration exposure in healthy subjects induced an increase in the levels of these adipokines. Thus, in healthy matched-group, the activation of innate and/or inflammatory responses (considered a "state of alert"), which is indispensable to prevent and defend against pathogenic attacks, could be interpreted as a positive physiological adaptation against a situation of vulnerability to the body (15).

In addition to adipokines, BDNF levels did not differ between groups. This finding is in line with the current literature that has shown that serum levels of BDNF did not differ significantly between patients with FM and controls (14). The action of this neurotrophin is closely linked to central and peripheral molecular processes of energy metabolism together with homeostasis associated with induction of a cascade of neurotrophic and neuroprotective effects (11). However, its role in FM as a possible enhancer or attenuator of pain is still controversial. Thus, despite the fact that activation of NMDAR (N-methyl-Daspartate: an inotropic receptor activated by glutamate/ aspartate) by endogenous BDNF appears to contribute to hyperalgesia by increasing awareness of dorsal neurons, the current literature indicates the role of BDNF as a mediator of pain through downregulation of TrkB receptors involved in pain modulation. However, this mechanism is 
not well understood in patients with FM and other chronic diseases (39).

Although BDNF levels did not differ between groups in this study, acute vibration exposure reduced plasma levels of BDNF in FM group. The literature shows that BDNF is produced by skeletal muscle cells in response to contraction, enhancing fat oxidation via activation of AMP-activated protein kinase (12). Physical activity seems to be a key intervention to trigger the processes through which neurotrophins mediate energy metabolism and their neural plasticity. According to Knaepen and colleagues (11), of all neurotrophins, BDNF seems to be the most susceptible to exercise and physical activities. Considering that the turnover of BDNF after low-intensity stimulation in patients with FM was not assessed, an explanation of this finding is beyond the scope of this study. However, we propose that the action of this neurotrophin modulates towards a greater adaptation to stress response in these patients.

There are limitations in the interpretation of the results of our study. Despite the instruction to our volunteers in both groups to abstain from medication $8 \mathrm{~h}$ prior to the trial, it is not possible to completely exclude the effect of drugs on plasma levels of biomarkers. Moreover, we matched the group volunteers regarding the use of medications, especially the intake of glucocorticoids. Once there are many potential confounding factors in the level of cytokines (e.g., circadian rhythm, medication, physical activity, infections, body mass index, and mood state), we carefully and rigorously controlled the matching of FM and healthy women by age and anthropometric parameters. Finally, although some subjects in the FM group were taking antidepressant drugs that could activate monocytes

\section{References}

1. Wolfe F, Smythe HA, Yunus MB, Bennett RM, Bombardier $C$, Goldenberg DL et al. The American College of Rheumatology 1990 criteria for the classification of fibromyalgia. Arthritis Rheum 1990; 33: 160-172, doi: 10.1002/art.1780 330203.

2. Ortega E, García J, Bote M, Martín-Cordero L, Escalante Y, Saavedra JM et al. Exercise in fibromyalgia and related inflammatory disorders: known effects and unknown chances. Exerc Immunol Rev 2009; 15: 42-65.

3. Fatima G, Mahdi AA, Das SK, Anjum B, Verma NS, Kumar P et al. Lack of circadian pattern of serum TNF- $\alpha$ and IL- 6 in patients with fibromyalgia syndrome. Indian J Clin Biochem 2012; 27: 340-343, doi: 10.1007/s12291-012-0205-z.

4. Aderka D, Engelmann $H$, Maor $Y$, Brakebusch $C$, Wallach D. Stabilization of the bioactivity of tumor necrosis factor by its soluble receptors. T J Exp Med 1992; 175: 323-329, doi: 10.1084/jem.175.2.323.

5. Penninx BW, Abbas H, Ambrosius W, Nicklas BJ, Davis $C$, Messier SP et al. Inflammatory markers and physical function among older adults with knee osteoarthritis. J Rheumatol 2004; 31: 2027-2031. and macrophages, increasing the production of antiinflammatory cytokines (40), FM group showed a chronic inflammatory profile.

In conclusion, this study demonstrated that a single acute session of mild and short WBV can improve the inflammatory status in patients with $\mathrm{FM}$, reaching values close to healthy anthropometrically- and age-matched HW at their basal status. The neuroendocrine mechanism seems to be an exercise-induced modulation towards greater adaptation to stress response in these patients.

\section{Acknowledgments}

The authors are thankful to professor David Lee Nelson for kindly reading the manuscript, professor Alexandre Christófaro Silva, Faculdade de Ciências Agrárias da Universidade Federal dos Vales do Jequitinhonha e Mucuri (Diamantina, Brazil), for helping with the interpretation of data. The authors would also like to express their gratitude to the Centro Especializado em Reabilitação (CER IV Diamantina, MG, Brazil) and Sociedade Brasileira de Fisiologia (SBFis). Finally, the authors would like to acknowledge the Centro Integrado de Pós-Graduação e Pesquisa em Saúde at the Universidade Federal dos Vales do Jequitinhonha e Mucuri, Diamantina, MG, for providing equipment and technical support for experiments. This study was funded by Fundação de Amparo à Pesquisa de Minas Gerais (FAPEMIG; APQ-01720/14 and AUC-00011-16), Conselho Nacional de Desenvolvimento Científico e Tecnológico (CNPq; \#306988/2015-1), and Coordenação de Aperfeiçoamento de Pessoal de Nível Superior (CAPES) for financial support and scholarships.

6. Bjersing JL, Erlandsson M, Bokarewa MI, Mannerkorpi K. Exercise and obesity in fibromyalgia: beneficial roles of IGF-1 and resistin? Arthritis Res Ther 2013; 15: R34, doi: 10.1186/ ar4187.

7. Luo Y, Liu M. Adiponectin: a versatile player of innate immunity. J Mol Cell Biol 2016; 8: 120-128, doi: 10.1093/ $\mathrm{jmcb} / \mathrm{mjw} 012$.

8. Fantuzzi G, Faggioni R. Leptin in the regulation of immunity, inflammation, and hematopoiesis. J Leukoc Biol 2000; 68: 437-446.

9. Kaser S, Kaser A, Sandhofer A, Ebenbichler C, Tilg $H$, Patsch J. Resistin messenger-RNA expression is increased by proinflammatory cytokines in vitro. Biochem Biophys Res Commun 2003; 309: 286-290, doi: 10.1016/j.bbrc.2003. 07.003.

10. Bokarewa M, Nagaev I, Dahlberg L, Smith U, Tarkowski A. Resistin, an adipokine with potent proinflammatory properties. J Immunol 2005; 174: 5789-5795, doi: 10.4049/jimmunol. 174.9.5789.

11. Knaepen K, Goekint M, Heyman EM, Meeusen R. Neuroplasticity - exercise-induced response of peripheral 
brain-derived neurotrophic factor. Sports Med 2010; 40: 765-801, doi: 10.2165/11534530-000000000-00000.

12. Matthews V, Åström M-B, Chan M, Bruce CR, Krabbe KS, Prelovsek $O$ et al. Brain-derived neurotrophic factor is produced by skeletal muscle cells in response to contraction and enhances fat oxidation via activation of AMP-activated protein kinase. Diabetologia 2009; 52: 1409-1418, doi: 10.1007/s00125-009-1364-1.

13. Bathina S, Das UN. Brain-derived neurotrophic factor and its clinical implications. Arch Med Sci 2015; 11: 1164-1178, doi: 10.5114/aoms.2015.56342.

14. Ranzolin A, Duarte ALBP, Bredemeier M, da Costa Neto CA, Ascoli BM, Wollenhaupt-Aguiar B et al. Evaluation of cytokines, oxidative stress markers and brain-derived neurotrophic factor in patients with fibromyalgia-A controlled cross-sectional study. Cytokine 2016; 84: 25-28, doi: 10.1016/j.cyto.2016.05.011.

15. Bote ME, Garcia JJ, Hinchado MD, Ortega E. Fibromyalgia: anti-inflammatory and stress responses after acute moderate exercise. PloS one 2013; 8: e74524, doi: 10.1371/journal. pone. 0074524 .

16. Torgrimson-Ojerio B, Ross RL, Dieckmann NF, Avery S, Bennett RM, Jones KD et al. Preliminary evidence of a blunted anti-inflammatory response to exhaustive exercise in fibromyalgia. J Neuroimmunol 2014; 277: 160-167, doi: 10.1016/j.jneuroim.2014.10.003.

17. Collado-Mateo D, Adsuar JC, Olivares PR, Del Pozo-Cruz B, Parraca JA, Del Pozo-Cruz J et al. Effects of whole-body vibration therapy in patients with fibromyalgia: a systematic literature review. J Evid Based Complementary Altern Med, 2015; 2015: 719082, doi: 10.1155/2015/719082.

18. Pinto NDS, Monteiro MOB, Paiva DN, Santos-Filho SD, Misssailidis $S$, Thompson $D$ et al. Fibromyalgia and the relevance of the whole-body vibration exercises in vibratory platforms: a short review. Braz Arch Biol Technol 2012; 55: 61-67, doi: 10.1590/S1516-89132012000100007.

19. Cochrane D. Vibration exercise: the potential benefits. Int $J$ Sports Med 2011; 32: 75-99, doi: 10.1055/s-0030-1268010.

20. Paiva ES, Heymann RE, Rezende MC, Helfenstein M Jr, Martinez JE, Provenza JR et al. A Brazilian Portuguese version of the Revised Fibromyalgia Impact Questionnaire (FIQR): a validation study. Clin Rheumatol 2013; 32: 11991206, doi: 10.1007/s10067-013-2259-6.

21. Gomes-Oliveira MH, Gorenstein C, Lotufo Neto F, Andrade $\mathrm{LH}$, Wang YP. Validation of the Brazilian Portuguese version of the Beck Depression Inventory-II in a community sample. Rev Bras de Psiquiatr 2012; 34: 389-394, doi: 10.1016/j.rbp. 2012.03.005.

22. Jones CJ, Rikli RE, Beam WC. A 30-s chair-stand test as a measure of lower body strength in community-residing older adults. Res Q Exerc Sport 1999; 70: 113-119, doi: 10.1080/ 02701367.1999.10608028.

23. Avelar NCP, Simão AP, Tossige-Gomes R, Neves CD, Rocha-Vieira E, Coimbra CC et al. The effect of adding whole-body vibration to squat training on the functional performance and self-report of disease status in elderly patients with knee osteoarthritis: a randomized, controlled clinical study. J Altern Complement Med 2011; 17: 1149-1155, doi: 10.1089/acm.2010.0782

24. Olivares PR, Gusi N, Parraca JA, Adsuar JC, Del Pozo-Cruz B. Tilting whole body vibration improves quality of life in women with fibromyalgia: a randomized controlled trial.
J Altern Complement Med 2011; 17: 723-728, doi: 10.1089/ acm.2010.0296.

25. Garrow JS, Webster J. Quetelet's index $(\mathrm{W} / \mathrm{H} 2)$ as a measure of fatness. Int J Obes 1985; 9: 147-153.

26. Delecluse $C$, Roelants $M$, Verschueren $S$. Strength increase after whole-body vibration compared with resistance training. Med Sci Sports Exerc 2003; 35: 1033-1041, doi: 10.1249/01. MSS.0000069752.96438.B0.

27. Borg GA. Psychophysical bases of perceived exertion. Med Sci Sports Exerc 1982; 14: 377-381.

28. Steel RG, James HT, Dickey JH. Pinciples and procedures of statistics a biometrical approach. 3rd Sub edn. New York: McGraw-Hill Companies; 1980.

29. Garber CE, Blissmer B, Deschenes MR, Franklin BA, Lamonte MJ, Lee IM et al. American College of Sports Medicine position stand. Quantity and quality of exercise for developing and maintaining cardiorespiratory, musculoskeletal, and neuromotor fitness in apparently healthy adults: guidance for prescribing exercise. Med Sci Sports Exerc 2011; 43: 1334-1359, doi: 10.1249/MSS.0b013e318213fefb.

30. Nagy K, Nagaraju SP, Rhee CM, Mathe Z, Molnar MZ. Adipocytokines in renal transplant recipients. Clin Kidney $\mathrm{J}$ 2016; 9: 359-373, doi: 10.1093/ckj/sfv156.

31. Sente T, Van Berendoncks AM, Hoymans VY, Vrints CJ. Adiponectin resistance in skeletal muscle: pathophysiological implications in chronic heart failure. J Cachexia Sarcopenia Muscle 2016; 7: 261-274, doi: 10.1002/jcsm.12086.

32. Park P-h, McMullen MR, Huang H, Thakur V, Nagy LE. Short-term treatment of RAW264.7 macrophages with adiponectin increases tumor necrosis factor- $\alpha$ (TNF- $\alpha$ ) expression via ERK1/2 activation and Egr-1 expression role of TNF- $\alpha$ in adiponectin-stimulated interleukin-10 production. $J$ Biol Chem 2007; 282: 21695-21703, doi: 10.1074/jbc.M701419200.

33. Yamauchi T, Iwabu M, Okada-Iwabu M, Kadowaki T. Adiponectin receptors: a review of their structure, function and how they work. Best Pract Res Clin Endocrinol Metab 2014; 28: 15-23, doi: 10.1016/j.beem.2013.09.003.

34. Lee S, Kwak H-B. Effects of interventions on adiponectin and adiponectin receptors. J Exerc Rehabil 2014; 10: 60-68, doi: 10.12965/jer.140104.

35. Goldstein BJ, Scalia R. Adiponectin: a novel adipokine linking adipocytes and vascular function. J Clin Endocrinol Metab 2004; 89: 2563-2568, doi: 10.1210/jc.2004-0518.

36. Shehzad A, Iqbal W, Shehzad O, Lee YS. Adiponectin: regulation of its production and its role in human diseases. Hormones 2012; 11: 8-20.

37. Ouchi N, Parker JL, Lugus JJ, Walsh K. Adipokines in inflammation and metabolic disease. Nat Rev Immunol 2011; 11: 85-97, doi: 10.1038/nri2921.

38. Liao Y, Takashima S, Maeda N, Ouchi N, Komamura K, Shimomura $\mathrm{I}$ et al. Exacerbation of heart failure in adiponectin-deficient mice due to impaired regulation of AMPK and glucose metabolism. Cardiovasc Res 2005; 67: 705-713, doi: 10.1016/j.cardiores.2005.04.018.

39. Nugraha B, Korallus C, Gutenbrunner C. Serum level of brain-derived neurotrophic factor in fibromyalgia syndrome correlates with depression but not anxiety. Neurochem Int 2013; 62: 281-286, doi: 10.1016/j.neuint.2013.01.001.

40. Sumpton JE, Moulin DE. Fibromyalgia: presentation and management with a focus on pharmacological treatment. Pain Res Manag 2008; 13: 477-483, doi: 10.1155/2008/959036. 